Revista Brasileira de Agricultura Irrigada v.11, nº.6, p. 1914 - 1923, 2017

ISSN 1982-7679 (On-line)

Fortaleza, CE, INOVAGRI - http://www.inovagri.org.br

DOI: $10.7127 /$ rbai.v11n600653

Protocolo 653.17 - 04/04/2017 Aprovado em 26/05/2017

\title{
PRODUÇÃO E QUALIDADE DE FRUTOS DO MELOEIRO CULTIVADO EM SISTEMA SEMI-HIDROPÔNICO
}

Karen Mariany Pereira Silva ${ }^{1}$, Christiano Rebouças Cosme $^{2}$, Nildo da Silva Dias ${ }^{2}$, Ítalo Sorac Rafael de Queiroz ${ }^{3}$, Adriana Araújo Diniz ${ }^{4}$, José Amilton Santos Junior ${ }^{5}$

\section{RESUMO}

O Estado do Rio Grande do Norte é o segundo maior exportador de melão do Brasil. O cultivo semi-hidropônico tem sido uma alternativa para melhorar a eficiência na produção, pois facilita a absorção de água e nutrientes pelas plantas. Com o objetivo de avaliar os efeitos da concentração de macronutrientes na solução nutritiva de plantas melão (Cucumis melo L., cv. Gália) em sistema semi-hidropônico, um experimento foi conduzido em cada de vegetação utilizando o delineamento experimental em blocos casualizados, com cinco tratamentos e cinco repetições. Os tratamentos concentrações de macronutrientes da solução nutritiva testados foram: 12,5; 25; 50;75 e 100\% do quantitativo de nutrientes proposto para o cultivo de melão. No final do experimento foram avaliados o peso médio de frutos, diâmetros transversal e longitudinal, cavidades internas transversal e longitudinal, espessura de casca e polpa, sólidos solúveis, acidez total titulável, $\mathrm{pH}$, açúcares totais e relação de maturação dos frutos. As análises dos resultados mostraram que a concentração de $75 \%$ da solução nutritiva padrão resultou em melhor peso médio de fruto e qualidade pós-colheita do melão.

Palavras-chave: cucumis melo l. cultivo sem solo, solução nutritiva.

\section{FRUIT YIELD AND QUALITY OF MELON PLANTS GROWN IN SEMI- HYDROPONIC SYSTEM}

\footnotetext{
ABSTRACT

The State of Rio Grande do Norte is the second largest exporter of melon in Brazil. The semihydroponic cultivation has become an alternative to improve the efficiency production due

${ }^{1}$ Doutoranda do Programa de Pós-Graduação em Fitotecnia da Universidade Federal Rural do Semi-Árido, PPGFITO/UFERSA, e-mail: karenmariany@gmail.com

${ }^{2}$ Professores Doutores da Universidade Federal Rural do Semi-Árido (UFERSA), e-mail: christianoreboucas@ufersa.edu.br; nildo@ufersa.edu.br.

${ }^{3}$ Mestre em Manejo de Solo e Água da Universidade Federal Rural do Semi-Árido - PPGMSA/UFERSA, e-mail: italosorac@hotmail.com.

${ }^{4}$ Professora Doutora da Universidade Estadual do Maranhão (UEMA), e-mail: adrsolos@bol.com.br.

${ }^{5}$ Professor Doutor da Universidade Federal Rural do Pernambuco (UFRPE), e-mail: eng.amilton@hotmail.com.
} 
facility in water and nutrient uptake by plants. In order to evaluate the effects of the macronutrient concentration in nutrient solution of melon plants (Cucumis melo L., cv. Galia) grown in semi-hydroponic system, an experiment was carried out in greenhouse condition utilizing randomized blocks, with five treatments and five replications. The treatment macronutrient concentrations of nutrient solution applied were 12.5, 25, 50, 75 e 100\% from standard nutrient solutions to melon crop. The average weigh of fruit, transverse and longitudinal diameters, transverse and longitudinal internal cavities, rind and pulp thickness, total soluble solids, titratable acids, $\mathrm{pH}$, total sugars and maturation index were recorded at the end of the experiment. The analysis results of fruit yield and quality assessment indicated that the concentration $75 \%$ from standard nutrient solution provided average weigh and post-harvest quality of melon fruits.

Keywords: cucumis melo l., cultivation without soil, nutrient solution.

\section{INTRODUÇÃO}

O melão (Cucumis melo L.) pertence à família das Cucurbitaceae, uma olerícola que ocupa posição de destaque no agronegócio nacional, sendo uma das hortaliças mais consumidas no Brasil (AGRIANUAL, 2014). Em 2015 o melão liderou entre as frutas frescas exportadas pelo Brasil (FAO, 2015), onde cerca de $45 \%$ da produção estava concentrada no estado do Rio Grade do Norte (IBGE, 2015). Diante da importância desta cultura para a região, há uma grande demanda de informações visando definir um sistema produtivo que apresente redução de custos, aumente a produtividade, e alcance os padrões mínimos de qualidade dos frutos exigidos no mercado internacional, sendo este um dos grandes desafios da fruticultura brasileira.

As informações em relação à nutrição do meloeiro, em especial do tipo rendilhado, bem como a variabilidade das respostas das cultivares quanto à extração de macro e micronutrientes, ressaltam a importância do estudo de extração de nutrientes (KANO et al., 2010). Em geral, os nutrientes mais exigidos pelo meloeiro são o $\mathrm{K}, \mathrm{N}$, e $\mathrm{Ca}$, que dependendo da variedade, podem ocupar diferentes posições entre si em termos de quantidades extraídas pela cultura (MELO et al., 2013).

No cultivo de melão rendilhado em hidroponia, Purquerio et al. (2003) verificaram que aumentos na concentração de $\mathrm{N}$ da solução nutritiva de 80 a $300 \mathrm{mg} \mathrm{L^{-1 }}$ promoveram maiores percentuais de massa na parte aérea em relação ao total acumulado pela planta, com reflexo negativo no acúmulo de massa do fruto. Também observaram pequeno aumento na acidez titulável dos frutos, sem afetar significativamente o teor de sólidos solúveis, quando a concentração de $\mathrm{N}$ passou de 80 a 300 $\mathrm{mg} \mathrm{L^{-1 }}$.

Andriolo et al. (2005) trabalharam com a seguinte composição média de macronutrientes em mmol L-1 em meloeiro: 13,0 de $\mathrm{NO}^{-}{ }^{-}$, 0,90 de $\mathrm{H}_{2} \mathrm{PO}_{4}, 6,00$ de $\mathrm{K}, 5,01$ de $\mathrm{Ca}, 2,25$ de $\mathrm{Mg}$ e 2,25 de $\mathrm{SO}_{4}^{-}$; e de micronutrientes, em $\mu \mathrm{mol} \mathrm{L}{ }^{-}$ 1: 33,50 de Fe, 15,00 de Mn, 2,30 de Zn, 1 de $\mathrm{Cu}, 14,80$ de $\mathrm{B}$ e 0,52 de Mo. Os autores observaram que a produtividade de frutos aumentou com o aumento da concentração da solução nutritiva, com produtividade máxima estimada na concentração de 44,10 $\mathrm{mmol} \mathrm{L}^{-1}$ de íons macronutrientes e uma condutividade elétrica da solução nutritiva drenada estimada de 3,90 dS m $\mathrm{m}^{-1}$. A firmeza da polpa e o teor de sólidos solúveis totais foram mais elevados com as concentrações de nutrientes superiores à testemunha.

O cultivo sem solo veio revolucionar a produção de hortaliças, principalmente, devido a possibilidade de se ter um maior controle dos fatores de produção, particularmente, sobre a administração de água e nutrientes. Adicionalmente, os sistemas de cultivos sem solo apresentam uma alta eficiência, sobretudo aqueles que permitem a reutilização da solução nutritiva e o uso de substratos de fácil reciclagem (DUARTE et al., 2008).

Tendo em vista que os reduzido números de pesquisas e o aumento do número de produtores tem gerado uma grande demanda por 
informações técnicas sobre a cultura, principalmente relacionadas com a nutrição mineral e a condução da planta. Desse modo, objetivou-se avaliar os efeitos da aplicação de diferentes concentrações de solução nutritiva sobre a produção de híbridos de melão rendilhado cultivados em sistema semihidropônico em ambiente protegido na região de Mossoró-RN.

\section{MATERIAL E MÉTODOS}

O experimento foi realizado em casa de vegetação no período de junho a agosto de 2014, no Departamento de Ciências Ambientais e Tecnológicas da Universidade Federal Rural do Semiárido - UFERSA, em Mossoró-RN (5 $11^{\prime}$ de latitude sul e $37^{\circ} 20^{\prime}$ de longitude oeste e altitude média de $18 \mathrm{~m}$ ). O clima da região, na classificação de Köppen, é do tipo BSwhee, (quente e seco), com precipitação pluviométrica bastante irregular, média anual de 673,9 mm; temperatura de $27^{\circ} \mathrm{C}$ e umidade relativa do ar média de 68,9\% (CARMO FILHO \& OLIVEIRA, 1995). Foi utilizado no experimento o melão tipo Gália cultivar "Néctar".

O delineamento experimenta adotado foi o de blocos casualizados, referente a cinco tratamentos e cinco repetições, compondo 25 parcelas experimentais. Cada parcela experimental constou de 4 plantas, contidas em vasos, espaçados em $0,5 \mathrm{~m}$ na fila e $1,0 \mathrm{~m}$ entre filas. O experimento foi conduzido em vasos de $5 \mathrm{~L}$ preenchidos com fibra de coco que serviram de meio de crescimento para as plantas. Em cada vaso foram feitas perfurações na base e adicionada uma camada de $3 \mathrm{~cm}$ de brita coberta com manta geotêxtil (Bidim) para permitir a drenagem do excesso de água aplicada nas irrigações.

Os tratamentos eram compostos de cinco soluções nutritivas diferentes quanto à concentração de macronutrientes, variando em proporções $\left(\mathrm{T}_{1}=100, \mathrm{~T}_{2}=75, \mathrm{~T}_{3}=50 \mathrm{~T}_{4}=25 \%\right.$ e $\mathrm{T}_{5}=12,5 \%$ da solução padrão proposta por Furlani et al. (1999),(Tabela 1).

Tabela 1 - Composição das soluções nutritivas dos tratamentos com base na solução padrão de Furlani et al. (1999).

\begin{tabular}{|c|c|c|c|c|c|c|c|c|c|c|c|c|}
\hline \multirow{2}{*}{$\begin{array}{c}\text { Proporções } \\
\text { (\%) }\end{array}$} & \multicolumn{12}{|c|}{ Elementos Químicos da solução } \\
\hline & $\mathrm{N}-\mathrm{NO}^{3-}$ & $P$ & $\mathrm{~K}$ & $\mathrm{Ca}$ & $\mathrm{Mg}$ & $\mathrm{S}$ & $\mathrm{B}$ & $\overline{\mathrm{Cu}}$ & $\mathrm{Fe}$ & $\mathrm{Mn}$ & Mo & $\mathrm{Zn}$ \\
\hline & & 8 & & & & & & ng- & & ----- & & \\
\hline 12,5 & 26,31 & 6,25 & 33,75 & 21,25 & 5,0 & 6,5 & 0,5 & 0,1 & 2,2 & 0,5 & 0,05 & 0,3 \\
\hline 25,0 & 52,6 & 12,5 & 67,5 & 42,5 & 10,0 & 13,0 & 0,5 & 0,1 & 2,2 & 0,5 & 0,05 & 0,3 \\
\hline 50,0 & 105,25 & 25,0 & 135,0 & 85,0 & 20,0 & 26,0 & 0,5 & 0,1 & 2,2 & 0,5 & 0,05 & 0,3 \\
\hline 75,0 & 157,87 & 37,5 & 202,5 & 127,5 & 30,0 & 39,0 & 0,5 & 0,1 & 2,2 & 0,5 & 0,05 & 0,3 \\
\hline 100 & 210,5 & 50,0 & 270,0 & 170,0 & 40,0 & 52,0 & 0,5 & 0,1 & 2,2 & 0,5 & 0,05 & 0,3 \\
\hline
\end{tabular}

Após a colheita, os frutos foram colocados em caixas, e transportados para o laboratório Multidisciplinar de Agricultura Irrigada da Universidade Federal Rural do Semiárido, UFERSA, em Mossoró, RN, onde foram selecionados e analisados.

Para a avaliação da qualidade pós-colheita dos frutos foram selecionados um fruto por planta, totalizando quatro frutos por repetição, consequentemente sendo avaliados cinquenta frutos. Para as avaliações físicas foram realizadas medições individuais, em seguida, esses mesmos frutos foram processados e submetidos à avaliações químicas. Os parâmetros avaliados foram: peso do fruto, cavidade interna transversal (CT); cavidade interna longitudinal (CL); diâmetro transversal (DT); diâmetro longitudinal (DL), espessura da casca (EC); espessura de polpa (EP); Acidez; Açúcar total (AT); Sólidos solúveis (SS); pH e índice de maturação (AT/SS).

Os dados obtidos foram submetidos à análise de variância e comparação de médias pelo teste de Tukey, a 5\% de probabilidade. As correlações lineares e regressões entre variáveis, quando apropriado, foram estabelecidas e consideradas significativas quando $\mathrm{P} \leq 5 \%$. Os softwares utilizados foram o Assistat ${ }^{\circledR}$, 
além do Microsof Excel ${ }^{\circledR}$ para confecção de gráficos.

\section{RESULTADOS E DISCUSSÕES}

O rendimento do melão foi significativamente influenciado pela concentração de nutrientes da solução nutritiva.
A dose limite da cultura para o parâmetro peso médio de frutos foi obtida com a aplicação de solução de $50 \%$ do padrão, que atingiu melhor peso de aproximadamente $0,789 \mathrm{~kg}$ planta $^{-1}$. Obtendo-se uma boa produtividade média de 0,705 kg (Figura 1). Doses acima de 50\% promoveram a diminuição do peso do fruto, sendo este fato observado nos tratamentos $\mathrm{T}_{1}$ (100\%) e $\mathrm{T}_{2}(75 \%)$.

Tabela 2: Análise de variância para as variáveis Peso médio dos frutos (PMF), Espessura da casca (EP); Espessura de polpa (EP); Cavidade interna longitudinal (CL); Cavidade interna transversal (CT); Diâmetro longitudinal (DL); Diâmetro transversal (DT) e Firmeza (FIRM) em função das proporções de nutrientes da solução nutritiva para o melão Gália.

\begin{tabular}{cccccccccc}
\hline \multicolumn{10}{c}{ QM } \\
\hline FV & GL & PMF & E.C & E.P & C.L & C.T & D.L & D.T & FIRM \\
Blocos & 4 & $0,007^{\text {ns }}$ & $0,002^{\text {ns }}$ & $0,011^{\text {ns }}$ & $0,27^{\text {ns }}$ & $0,03^{\text {ns }}$ & $0,22^{\text {ns }}$ & $0,35^{\text {ns }}$ & $8,19^{\text {ns }}$ \\
Tratamentos & 4 & $0,032^{*}$ & $0,006^{*}$ & $0,22^{* *}$ & $0,49^{*}$ & $0,44^{* *}$ & $0,74^{\text {ns }}$ & $0,59^{\text {ns }}$ & $20,08^{\text {ns }}$ \\
Resíduo & 16 & 0,009 & 0,002 & 0,03 & 0,15 & 0,07 & 0,29 & 0,25 & 13,82 \\
Total & 24 & & & & & & & & \\
CV(\%) & & $14,16 \%$ & $36,85 \%$ & 6,78 & $5,21 \%$ & $5,71 \%$ & $4,80 \%$ & $4,73 \%$ & $10,91 \%$ \\
\hline
\end{tabular}

As características relacionadas com a qualidade dos frutos são diretamente afetadas pelas condições de cultivo (SALES JÚNIOR et al., 2006), bem como local de plantio, preparo do solo, variedade, condições climáticas, época de plantio, cuidados no plantio, manejo e tratos culturais, densidade de plantio e adubação equilibrada. Assim como cuidados na colheita, além de diversos outros fatores pós-colheita (MENEZES et al., 2000).

Purquerio et al. (2003), estudando o cultivo de melão rendilhado em hidropônia, verificaram que o aumento na concentração de nitrogênio da solução nutritiva promoveu redução na produtividade comercial, sendo ainda observada redução do peso médio do fruto com elevação da disponibilidade do nutriente. As alterações manifestadas sobre a fisiologia da planta, e expressas principalmente no crescimento vegetativo, podem afetar a qualidade dos frutos (PURQUEIRO FILHO; CECILIO FILHO, 2005). Bonetti, et. al. (2011), estudando a influência do parcelamento de potássio nas características do melão utilizando o sistema de tutoramento, observou que a máxima produtividade foi estimada foi de em $45.712 \mathrm{~kg} \mathrm{ha}^{-1}$ de frutos, obtida com a dose de $136,75 \mathrm{~kg}$ de $\mathrm{K}_{2} \mathrm{O} \mathrm{ha}^{-1}$. Após esta dosagem, houve efeito depressivo quanto à produtividade de frutos.

Os resultados deste trabalho corroboram com os de diversos autores que obtiveram aumento do número de frutos e, consequentemente, da produtividade, com a elevação das doses de nitrogênio, ocasionando um comportamento polinomial dos resultados, onde o número de frutos e a produtividade diminuíram a partir de uma determinada dosagem (QUEIROGA et al., 2007; FOGAÇA et al. 2007; OLIVEIRA et al., 2008; NETO et al., 2012).

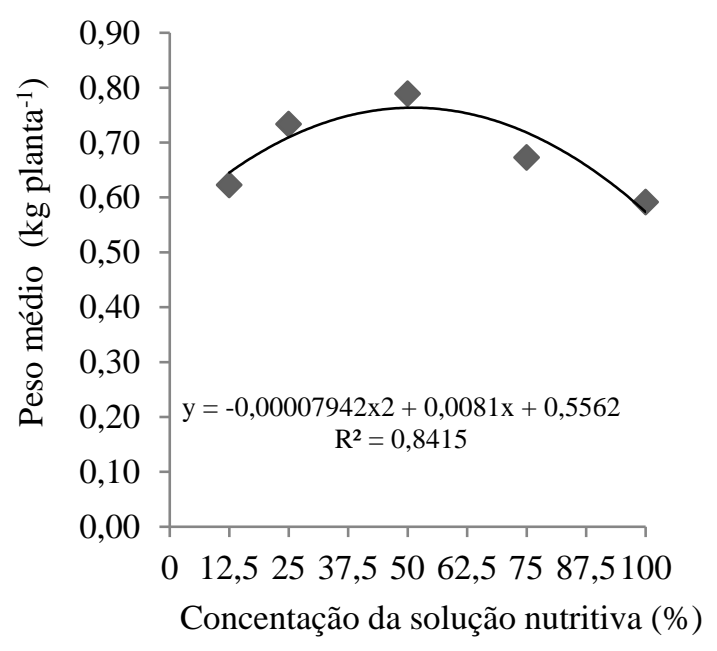

Figura 1. Peso médio dos frutos em função da 
solução nutritiva do meloeiro cultivado em substrato de fibra de coco.

Avaliando-se os parâmetros de espessura de Polpa (EP), observou-se que o tratamento $\mathrm{T}_{3}$ (50\%) apresentou-se superior aos demais tratamentos, obtendo variação de $(3,1-2,6 \mathrm{~cm})$, e média igual a 2,8 (mm), (Figura 2). Vilela (2010), afirma que a maior espessura da polpa é desejável pois aumenta o peso e a parte comestível, melhorando a qualidade do fruto. Os melões do tipo cantaloupensis possuem espessura de polpa de aproximadamente $25 \mathrm{~mm}$. Purqueiro e Cecílio Filho (2005), avaliando a concentração de nitrogênio na solução nutritiva e número de frutos sobre a qualidade dos frutos de melão, observaram que o aumento da concentração de nitrogênio na solução nutritiva promoveu reduções na espessura do mesocarpo obtendo uma variação de (31-28 mm).

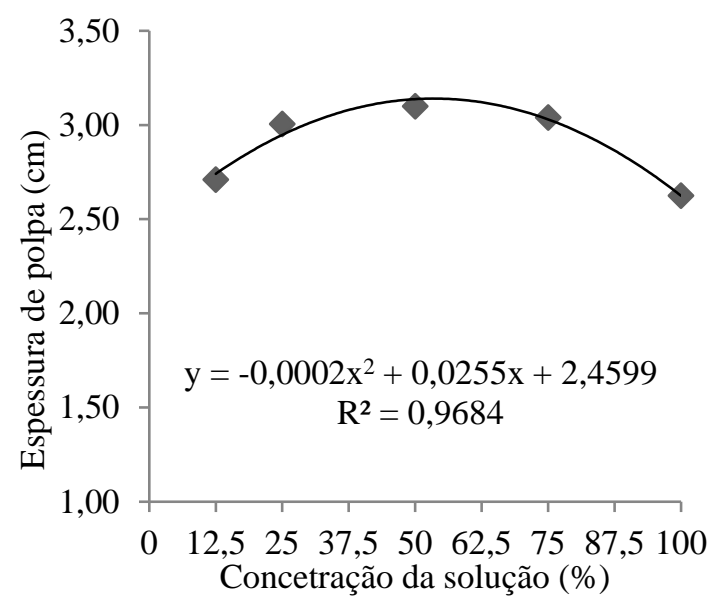

Figura 2. Espessura de polpa em função da solução nutritiva do meloeiro cultivado em substrato de fibra de coco.

Para espessura de casca (EC), o tratamento $\mathrm{T}_{1}$ (100\%), apresentou os maiores resultados, obtendo uma variação de (1,9-1,0 mm), e média de $1,9(\mathrm{~mm})$. O efeito da solução nutritiva em função da espessura da casca apresentou um aumento linear $(<0,05)$ em resposta ao incremento de nutrientes na solução nutritiva. Portanto, doses acima de $50 \%$ da solução nutritiva recomendados, acarretaram no aumento da espessura da casca e consequentemente a diminuição da polpa (Figura 3).
Segundo Queiroga et al. (2013), a espessura da casca é um parâmetro considerado importante para determinar a qualidade do melão, uma vez que o percentual de aproveitamento do fruto decorre da maior relação espessura de polpa/casca. Ainda que baixo rendimento de casca seja apreciado por se relacionar com melhor aproveitamento de polpa, este fator pode se constituir uma característica limitante ao processo de embalagem e transporte. Frutos com casca muito delgada apresentam alta sensibilidade ao manuseio e tende a sofrer danos internos na polpa, levando o fruto a uma depreciação da estrutura física interna e redução de período de estocagem.

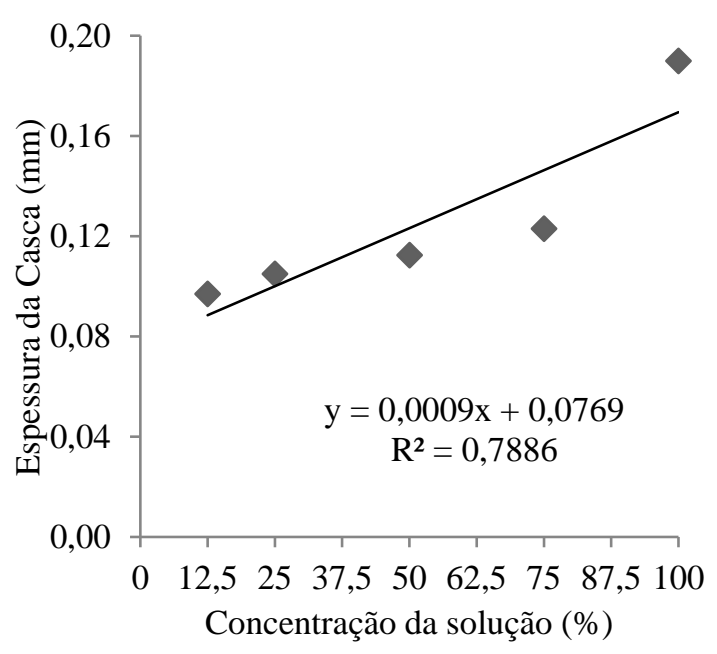

Figura 3. Espessura da casca em função da solução nutritiva no meloeiro cultivado em substrato de fibra de coco.

Na figura 4, são mostrados os efeitos da solução nutritiva sobre as variáveis cavidade interna longitudinal (CL). Pode-se observar que doses acima de $\mathrm{T}_{3}(50 \%)$ apresentaram efeitos semelhantes, ocasionando na redução das cavidades. A CT, obteve uma variação de $(5,14$ - 4,46 cm), sendo as menores cavidades obtidas pelos tratamentos $\mathrm{T}_{1}$ e $\mathrm{T}_{2}$, com 4,46 e 4,57 cm, respectivamente. Para a CL, o tratamento $\mathrm{T}_{2}$ (75\%) obteve a menor CL com 7,0 cm, observando-se uma variação de $(7-7,76 \mathrm{~cm})$, e média de 7,35 $(\mathrm{cm})$. Resultados próximos aos obtidos nesse trabalho foram observados por Charlo (2010), quando estudando desempenho de híbridos de melão rendilhado em substratos, observou-se para o diâmetro transversal: 
híbridos Jab 0724 (6,65) e Jab 0717 (5,03). Esses valores estão próximos aos encontrados por Rizzo \& Braz (2004), que verificaram diâmetros variando de 5,0 a $6,6 \mathrm{~cm}$.

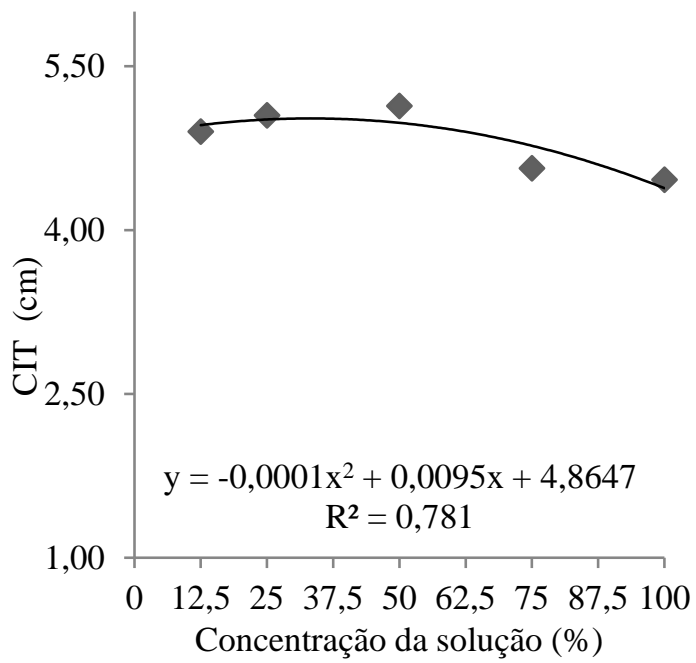

Figura 4. Cavidade interna longitudinal em função da solução nutritiva no meloeiro cultivado em substrato de fibra de coco.

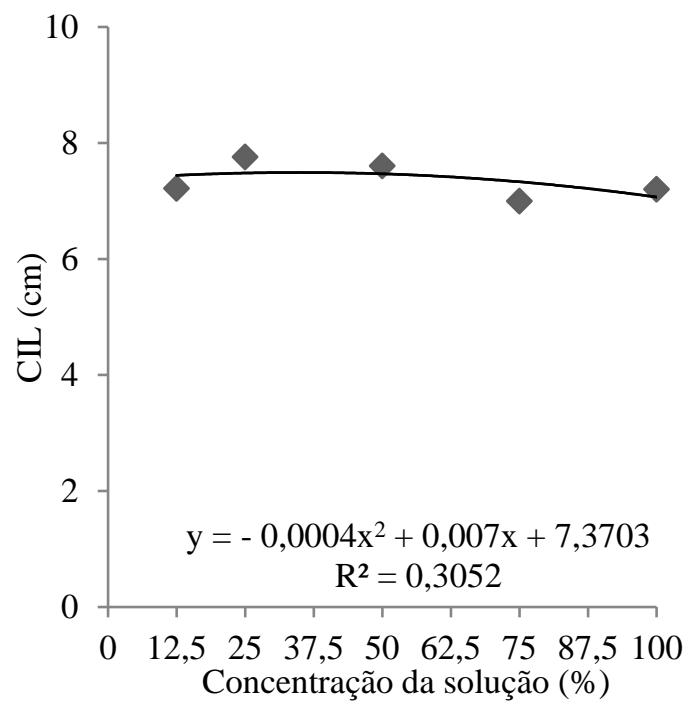

Figura 5. Cavidade interna longitudinal em função da solução nutritiva no meloeiro cultivado em substrato de fibra de coco.
Para frutos de qualidade, desejam-se menores valores de diâmetro longitudinal e transversal do lóculo, pois estes parâmetros indicam as dimensões da cavidade interna dos frutos, e assim sendo, quanto menor for esta característica, maior será o rendimento de polpa. Os frutos mais desejáveis são os que apresentam menor cavidade interna, pois maior é a tolerância ao transporte e vida útil pós-colheita em relação aos demais genótipos (NUNES et al., 2004).

Para a característica firmeza de polpa não foi observado efeito significativo para os tratamentos. A variação foi de (35,5-31,3 N), sendo a média igual a 34,4 N. Também não houve variação significativa entre os tratamentos para as variáveis diâmetro transversal (DT) e longitudinal (DL) do fruto. A variação foi de $(10,3-11,08 \mathrm{~cm})$ para DT, e $(10.7-11,7 \mathrm{~cm})$ para DL, médias obtidas foram de 10.7 e 11,3 cm, respectivamente. (Tabela 5). Morais et al. (2004) também não observaram diferenças significativas quanto ao comprimento e diâmetro nos híbridos de melão Gália 'Primal', 'Vicar', 'Total' e 'Solar King', que foram classifica dos como esféricos.

Na Tabela 5 encontram-se os valores de F, médias gerais e coeficientes de variação, referentes à Acidez $(\mathrm{NaOH})$, Açúcar total (AT), sólidos solúveis (SS), $\mathrm{pH}$ e a índice de maturação (AT/SS) dos tratamentos testados. Houve interação significativa $(<0,05)$ e $(<0,01)$ para as variável Acidez e (SS), respectivamente, ajustando-se ao modelo quadrático de regressão. As variáveis $\mathrm{pH}, \mathrm{AT} / \mathrm{SS}$ e AT não apresentaram resposta significativa, não se ajustando aos modelos de regressão.

Tabela 3: Análise de variância para as características químicas de pós-colheita, Acidez; Açúcar total (AT); Sólidos solúveis (SS); pH e índice de maturação (AT/SS) em função de diferentes doses de nutrientes no melão Gália cultivar "Néctar".

\begin{tabular}{ccccccc}
\hline \multicolumn{7}{c}{ QM } \\
\hline FV & GL & $\begin{array}{c}\text { ACIDEZ } \\
\left(\mathrm{mg} \mathrm{kg}^{-1}\right)\end{array}$ & A.T & $\begin{array}{c}\text { SS } \\
\left({ }^{\circ} \text { BRIX) }\right.\end{array}$ & pH & AT/SS \\
Blocos & 4 & $0,0009^{\text {ns }}$ & $1,25^{\text {ns }}$ & $2,22^{*}$ & $0,01^{\text {ns }}$ & $180,3^{\text {ns }}$ \\
Tratamentos & 4 & $0,006^{*}$ & $2,37^{\text {ns }}$ & $4,60^{* *}$ & $0,016^{\text {ns }}$ & $31,2^{\text {ns }}$ \\
Resíduo & 16 & 0,001 & 1,88 & 0,6 & 0,007 & 95,9 \\
Total & 24 & & & & & \\
\hline
\end{tabular}




\begin{tabular}{llllll}
\hline $\mathrm{CV}(\%)$ & $21,78 \%$ & $20,37 \%$ & $6,66 \%$ & $1,27 \%$ & $16,96 \%$ \\
\hline
\end{tabular}

Os valores médios de $\mathrm{pH}$ não se apresentaram significativamente diferentes entre os tratamentos analisados e variaram entre 6,9-6,75, apresentando média de 6,82 e coeficiente de variação igual a $1,27 \%$. Entretanto, esses valores estão próximos ao encontrado por Coelho et al. (2003) para melão rendilhado, $\mathrm{pH}$ médio de 6,83. Para Chitarra e Chitarra (2005), o pH é um parâmetro que se mensura de uma forma geral a acidez da fruta e dos alimentos, sendo este o indicador do tipo de tratamento necessário para se conservar os alimentos. O aumento do $\mathrm{pH}$ está diretamente relacionado com o decréscimo da acidez e com o avanço da maturação dos frutos.

Também não foram observados efeitos significativos para as variáveis Açúcar total (AT) e índice de maturação (AT/SS) em função dos tratamentos, apresentando uma variação de $(60,9-54,5)$ e $(7,72-5,86)$, e média de 51,3 e 6,88 respectivamente.

Para SS o tratamento $\mathrm{T}_{5} \quad(12,5 \%)$ apresentou diferença significativa para os demais tratamentos, obtendo uma média de $13^{\circ}$ Brix. Foi observada uma variação de 10,7 $13{ }^{\circ}$ Brix e uma média de $11,7^{\circ}$ Brix. O tratamento $\mathrm{T}_{2}$ (75\%) obteve a menor média (10,7 ${ }^{\circ}$ Brix) para SS, (Figura 5). O valor mínimo recomendado para os frutos de melão comercializados para a Europa é de $10^{\circ}$ Brix. No entanto, frutos com valores abaixo de $10{ }^{\circ} \mathrm{Brix}$ têm sido comercializados no porto de Natal. (SALES JÚNIOR et al. 2006).

Os resultados, corroboram com os dados obtidos por Aroucha, et al. (2009), que observaram valores iniciais de 10,95 a 12,28 ${ }^{\circ}$ Brix para melões do tipo Gália. Independente do tratamento, os frutos apresentaram boa qualidade para a comercialização, verificada pelo teor de sólidos solúveis. Nascimento Neto et al. (2012) que ao avaliar o efeito de doses e formas de aplicação de nitrogênio em melão do tipo amarelo obteve valores de sólidos solúveis variando de 8,5 a $12{ }^{\circ}$ Brix.

Este resultado pode ser explicado pela influência do potássio sobre o teor de sólidos solúveis. Esta influência tem sido discutida por diversos autores, Nascimento Neto (2011), verificou que o excesso de potássio no solo aplicado via fertirrigação diminuiu o teor de sólidos solúveis dos frutos de melão amarelo híbrido Gold Mine, e pela regressão, estimou-se o máximo valor de SS de $11^{\circ}$ Brix com uma dose de potássio de 253,88 $\mathrm{kg} \mathrm{ha}^{-1}$.

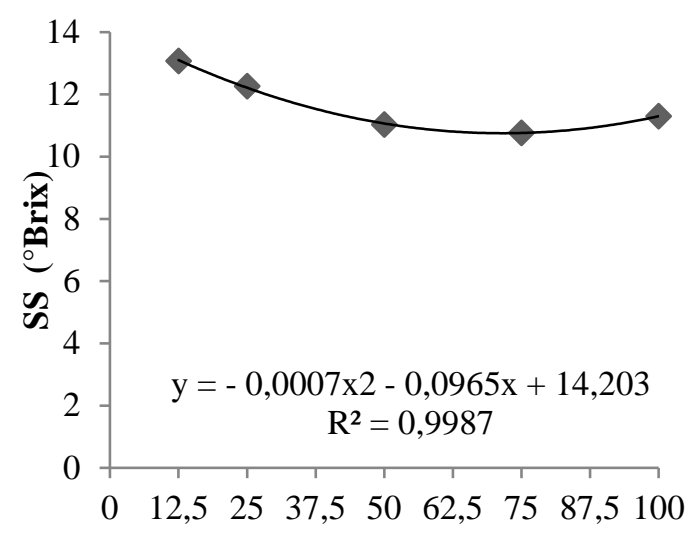

Concentração da solução (\%)

Figura 5: Teor de sólidos solúveis em função da solução nutritiva no meloeiro cultivado em substrato de fibra de coco.

A acidez total titulável obteve uma variação de $0,23-0,17 \mathrm{mg} \mathrm{L}^{-1}$, apresentando uma média de $0.18 \mathrm{mg} \mathrm{L}^{-1}$. $\mathrm{O}$ tratamento $\mathrm{T}_{2}$ (75\%) apresentou os menores resultados, obtendo-se uma de $0,13 \mathrm{mg} \mathrm{L}^{-1}$, seguido de $\mathrm{T}_{1}$ (100) com (0,17 $\left.\mathrm{mg} \mathrm{L}^{-1}\right)$ (Figura 6). A perda de acidez é considerada por Silva (2004) como desejável em grande parte dos frutos e importante para o processo de amadurecimento, onde são provavelmente convertidos em açúcares. Albuquerque et al. (2006), afirmam que os ácidos orgânicos realçam juntamente com os açúcares a percepção do flavor especifico dos melões. No entanto, Fernandes (2010) trabalhando com frutos de melão híbrido amarelo em função dos sistemas de plantio e estratégias de manejo de plantas daninhas, relatou valores médios de acidez titulável, entre 0,18 e 0,26\% de ácido cítrico. Barreto (2011) obteve os maiores valores médios de porcentagem de ácido cítrico $(0,15 \%)$ foram encontrados nas polpas dos híbridos ‘Goldex’ e 
'Melidol' tipos Amarelo e Gália, respectivamente.

De maneira geral, os valores verificados para a acidez total neste trabalho estão de acordo com as quantidades de ácido cítrico observados em melões, que variam de 0,05 a $0,35 \%$ do ácido cítrico (Costa et al., 2004). Na maioria dos frutos, a acidez representa um dos principais componentes do flavor, pois sua aceitação depende do balanço entre ácidos e açúcares, sendo que a preferência incide sobre altos teores desses constituintes. No melão, a variação nos níveis de acidez tem pouco significado em função da baixa concentração, e a intervenção da acidez no sabor não é muito representativa (Morais et al., 2009).

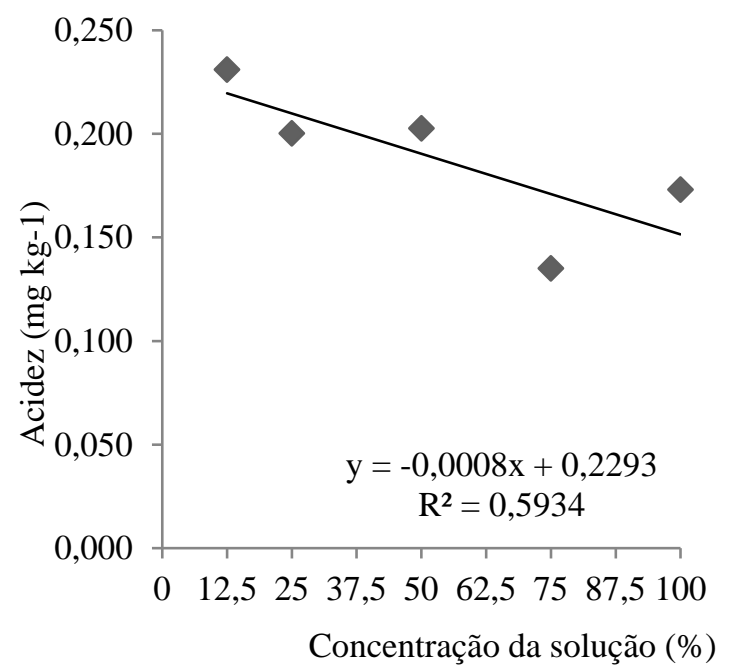

Figura 6. Acidez total titulável em função da solução nutritiva no meloeiro cultivado em substrato de fibra de coco.

Por fim, observou-se que a produção e qualidade pós-colheita dos frutos do meloeiro em sistema hidropônico foi influenciada pela concentração da solução nutritiva. O aumento da concentração de nutrientes reduziu o peso médio dos frutos, diâmetro da haste, espessura da polpa, cavidade interna longitudinal e transversal, sólidos solúveis e acidez dos frutos, e aumentou a espessura da casca.

\section{CONCLUSÕES}

As variáveis de produção e qualidade póscolheita dos frutos foram influenciadas pelas diferentes concentrações de nutrientes.

As análises dos resultados mostraram que a concentração de $75 \%$ da solução nutritiva resultou nos melhores resultados de peso médio de fruto e qualidade pós-colheita.

\section{REFERENCIAS}

AGRIANUAL 2011: Anuário da Agricultura Brasileira. São Paulo: FNP, Consultoria e Comércio, 355- 358p. 2011.

ANDRIOLO, J. L.; LUZ, G. L.; BORTOLOTTO, O. C.; GODOI, R. S. Produtividade e qualidade de frutos de meloeiro cultivado em substrato com três doses de solução nutritiva. Ciência Rural, Santa Maria, v. 35, n. 4, p. 781-787, 2005.

AROUCHA, E. M. M.; NUNES, G. H. DE S.; SOUSA, A. E. D. DE; FERNANDES, P. L. DE O.; SOUZA, M. S. DE. Qualidade e potencial pós-colheita de híbridos de melão. Revista Ceres. 56(2): 181-185, 2009.

\section{ALBUQUERQUE ET AL. Crep} evapotranspiration Guidelines for computing crep water requirements. Rome: FAO, 2006, 279 p. (FAO, Irrigation and Drainage Paper, 56). Alves, R. E. et al. Manual de melão para exportação. EMBRAPA. Brasília, DF, 2000. 51 p.

BARRETO, N. D. S.; Qualidade, compostos bioativos e capacidade antioxidante de frutos de híbridos comerciais de meloeiro cultivados no CE e RN. 2011. 185 f. Tese (Doutorado) Curso de Mestrado em Fitotecnia, Coordenação de Pós-graduação, Universidade Federal Rural do Semi-Árido, Mossoró, 2011.

CARMO FILHO, F. DO; OLIVEIRA, O.F. DE. Mossoró: um município do semi-árido nordestino, caracterização climática e aspecto florístico. Mossoró: ESAM, 1995. 62p. (Coleção Mossoroense, série B). 
CHARLO, H. C. de O. Desempenho de híbridos de melão rendilhado em substratos /. 2010. 51 f. Tese (Doutorado) - Curso de Doutorado em Agronomia, Faculdade de Ciências Agrárias e Veterinárias, Universidade Estadual Paulista, Jaboticabal, 2010.

COELHO, E. L.; FONTES, P. C. R.; FINGER, F. L.; CARDOSO, A. A. Qualidade do fruto de melão rendilhado em função de doses de nitrogênio. Bragantia, Campinas, v.62, n.2, p.173-178, 2003.

COSTA, C.C.; CECÍLIO FILHO, A. B.; CAVARIANI, R. L.; BARBOSA, J. C. Concentração de potássio na solução nutritiva e a qualidade e o número de frutos de melão por planta em hidroponia. Ciência Rural, Santa Maria, v.34, n.3, p.731-736, 2004.

DUARTE, T. S.; PEIL, R.M.N; MONTEZANO, E.M. Crescimento de frutos do meloeiro sob diferentes relações fonte: dreno. Horticultura Brasileira, Brasília, v. 26, n. 3, p.342-347, jul. 2008.

FERNANDES, D. Interferência de plantas daninhas na produção e qualidade de frutos de melão nos sistemas de plantio direto e convencional. 2010. 52p. Dissertação (Mestrado em Fitotecnia) - Universidade Federal Rural do Semiárido (UFERSA), Mossoró-RN, 2010.

FILGUEIRAS, H.A.C.; MENEZES, J.B.; ALVES, R.E.; COSTA, F.V.; PEREIRA, L.S.E.; GOMES JÚNIOR, J. Colheita e manuseio pós-colheita. In: Alves, R.E. (Org). Melão pós-colheita. Brasília: EMBRAPA-SPI, p. 23-41. (Frutas do Brasil, 10), 2000.

Food and Agriculture Organization of the United Nations - FAO. Faostat. Roma, 2015. Disponível em: <http://faostat3.fao.org/faostatgateway/go/to/compare/Q/QC/E $>$. Acesso em: 17 jul. 2015.

FOGAÇA, M.A.F.; ANDRIOLO, J.L.; GODOI, R.S.; GIEH, R.F.H.; MADALOZ, J.C.C.; BARROS, G.T. Concentração de nitrogênio na solução nutritiva, na produtividade e na qualidade de frutos de melão cultivado em substrato. Ciência Rural, v. 37, n. 1, p. 72-78, 2007.

FURLANI, P.R.; SILVEIRA, L.C.P.; BOLONHEZI, D.; FAQUIN, V. Cultivo Hidropônico de plantas. Campinas: Instituto Agronômico (IAC), 1999, 52p. (Boletim Técnico, 180).

INSTITUTO BRASILEIRO DE GEOGRAFIA E ESTATÍSTICA - IBGE. Estados, Censo Agropecuário 2006, Rio Grande do Norte. Brasília, 2015. Disponível em $<$ http://www.ibge.gov.br/estadosat/temas.php?s igla $=$ rn\&tema $=$ censoagro $>$. Acesso em: 17 jul. 2015.

KANO, C.; CARMELLO, Q. A. C.; CARDOSO, S. S.; FRIZZONE, J. A. Acúmulo de nutrientes pelo meloeiro rendilhado cultivado em ambiente protegido. Semina: Ciências Agrárias, Londrina, v. 31, p. 1155-1164, 2010.

MELO, D. M.; CHARLO, H. C. O.; CASTOLDI, R.; GOMES, R. F.; BRAZ, L. T. Acúmulo de nutrientes do meloeiro rendilhado 'Fantasy' cultivado em substrato. Semina: Ciências Agrárias, Londrina, v. 34, n. 4, p. 16731682, 2013.

MORAIS, P. L. D.; SILVA, GALDINO, G; MAIA, E. N.; MENEZES, J.B. Avaliação das tecnologias pós-colheita utilizadas e da qualidade de melões nobres produzidos para exportação. Ciência e Tecnologia de Alimentos, v.29, n.1, p.214-218, 2009

NASCIMENTO NETO, J.R. Formas de aplicação e doses de nitrogênio e potássio no cultivo do meloeiro amarelo. 2011. 77f. Dissertação (Mestrado em Engenharia Agrícola) - Universidade Federal do Ceará, 2011.

NETO, J.R.N.; BOMFIM, G.V.; AZEVEDO, B.M.; VIANA, T.V.A.; VASCONCELOS, D.V. Formas de aplicação e doses de nitrogênio para o meloeiro amarelo no litoral do Ceará. Irriga, Botucatu, v. 17, n. 3, p. 364-375, 2012. 
NUNES, G. H. S.; SANTOS JÚNIOR, J. J. S.; VALE, F. A.; BEZERRA NETO, F.; ALMEIDA, A. H. B.; MEDEIROS, D. C. Aspectos produtivos e de qualidade de híbridos de melão cultivados no agropolo Mossoró-Assú. Horticultura Brasileira, Brasília, v. 22, n. 4, p. 744-747, 2004.

OLIVEIRA, F.A.; MEDEIROS, J.F.; LIMA， C.J.G.S.; DUTRA, I.; OLIVEIRA, M.K.T. Eficiência agronômica da fertirrigação nitrogenada e potássica na cultura do meloeiro nas condições do semiárido nordestino. Revista Caatinga, Mossoró, v. 21, n. 5, p. 5-11, 2008.

PURQUERIO, L.F.V.; CECÍLIO FILHO, A.B.; BARBOSA, J.C. Efeito da concentração de nitrogênio na solução nutritiva e do número de frutos por planta sobre a produção do meloeiro. Horticultura Brasileira. Brasília, v. 21, n. 2, p. 185-190, abril/junho 2003.

PURQUERIO, L. F. CECÍLIOFILHO, A.B. Concentração de nitrogênio na solução nutritiva e número de frutos sobre a qualidade de frutos de melão.
Horticultura Brasileira, Brasília, v.23, n.3, p.831-836, jul-set 2005.

QUEIROGA, R.C.F.; PUIATTI, M.; FONTES, P. C. R.; CECON, P.R.; FINGER, F.L. Influência de doses de nitrogênio na produtividade e qualidade do melão Cantalupensissob ambiente protegido. Horticultura Brasileira, Brasília, v. 25, n. 4, p. 550-556, 2007.

QUEIROGA， F. M; NOVO JUNIOR, J; COSTA, S. A. D ; OLIVEIRA FILHO, PEREIRA. F.H. F ; SOUZAZ, A.L ; MARACAJA, P.B. Produção e qualidade de frutos de melão Harper em função de doses de boro, ACSA - Agropecuária Científica no Semi-Árido, v 9, n.3, p. 87 - 93, 2013.

SALES JÚNIOR, R.; DANTAS F. F.; SALVIANO A. M.; NUNES G. H.S. Qualidade do melão exportado pelo porto de Natal-RN. Ciência Rural, Santa Maria, v.36. n.1, p. 286289, jan./fev. 2006.

VILELA, P. Melão. Portal São Francisco. Disponível em: $<$ http://www.portalsaofrancisco.com.br/alfa/me lao/melao-2.php>. Acesso em: 21 jun. 2016 